\title{
Evaluating the effect of an educational program on increasing cervical cancer screening behavior among women in Fasa, Iran
}

\author{
Maryam Heidari Sarvestani ${ }^{1}$, Ali Khani Jeihooni ${ }^{2}$, Zahra Moradi ${ }^{3^{*}}$ (D) and Azizallah Dehghan ${ }^{4}$
}

\begin{abstract}
Background: Cervical cancer is the second most common cancer and the fifth deadliest cancer among women in Iran. Educational interventions based on the proper behavior promoting models can lead to early diagnosis of cervical cancer.This study aimed to investigate the effects of educational intervention on performing Pap smear tests based on the Theory of Planned Behavior among women living in Fasa, Iran.
\end{abstract}

Methods: A cross-sectional study was conducted on 700 participants. Thereafter, the educational intervention based on the results of cross-sectional study was conducted in a workshop form for 50 women as the intervention group and 50 women as the control group. Afterward, the data were entered into the SPSS statistical software and then analyzed via logistic regressions analysis, paired $t$ test, independent $t$ test, chi-square test, and McNemar test.

Result: According to the results, $45.7 \%$ of the patients had a history of performing a Pap smear test, and $20.7 \%$ of them regularly performed this test. The knowledge, attitude, subjective norms, and perceived behavioral control were the predictors of intention and behavior of Pap smear test among the women $(P<0.05)$. These components accounted for $57.4 \%$ and $31.6 \%$ of the intention and behavior variances, respectively. After the intervention, a significant increase was observed in the means of attitude, subjective norms, and perceived behavioral control in the intervention group compared to the control group. The results reveal no significant difference between these two groups regarding the behavioral intention $(p=0.41)$ and performance of the Pap smear test $(p=0.583)$. The number of the participants undergone the Pap smear test has increased from 10 to 26 in the intervention group by passing 3 months from the intervention. The results of McNemar test indicated that this difference was statistically significant.

Conclusion: The results indicated an increase in the women's performance of the Pap smear screening test by appropriate planning, provision of educational packages based on the women's needs, and using effective subjective norms.

Trial Registration: Current Controlled Trials IRCT20160830029608N3:12/31/2018. "Retrospectively registered".

Keywords: Pap smear, The theory of planned behavior, Women

*Correspondence: moradizahra427@yahoo.com

${ }^{3}$ Department of Nursing, School of Nursing, Fasa University of Medical

Sciences, Fasa, Iran

Full list of author information is available at the end of the article

\section{Background}

Cervical cancer is the second most common cancer and the fifth deadliest cancer among women in Iran [1]. Moreover, it is the most common cancer in developing countries. Annually, one out of every 123 women is infected with cervical cancer, with the mortality rate of 1 per 100/000 [2]. The World Health Organization (WHO) has estimated that cervical cancer will be responsible 
for $474 / 000$ deaths up to 2030 , with $95 \%$ of the deaths in low- and middle-income countries [3]. Nonetheless, considering the long pre-invasion period, accessibility of appropriate screening programs, and effective treatment of the primary lesions, cervical cancer is known as a preventable cancer [3]. By the utilization of Pap smear test as a screening technique, the prevalence of cervical cancer has reduced by $79 \%$ up to now [4]. Therefore, performance of this test should be considered as a health policy for those sexually active women [5]. Benedet et al. [6] maintained that the women undergone the Pap smear test more than 3 years ago and those who had not undergone the test at all, were at the highest risk for cervical cancer.

Educational interventions based on the proper behavior promoting models can lead to early diagnosis of cervical cancer, which eventually decreases the resultant mortality. Among the models used for the perception and prediction of health behaviors, the theory of planned behavior has been successful. The theory of reasoned action has also been designed to predict and explain behaviors based on the assumption that individuals select their behaviors in terms of the logical investigation of the available information and by considering the results of their performance prior to decision-making. According to this theory, the best predictor of behavior is the individual's intention for his/her involvement in the behavior. Correspondingly, intention is predicted by two variables; first, attitude related to the behavior (overall positive or negative evaluation of the behavior), and second, subjective norms (overall perception of social pressure to do the behavior). The rate of success of this theory in explaining the behavior mostly depends on the extent the behavior is controlled by the individual. In fact, individuals normally act based on their perception of how others think about what they should do. Besides, their intention to accept the behavior is potentially affected by those individuals with whom they have close relationships. In this theory, subjective norms are obtained through multiplying normative beliefs by the motivation of performing the target behavior, in contrast with the expectations. In addition, perceived behavioral control has been defined as the extent to which an individual believes about the controllability of a behavior [7-10]. In the present study, the theory of planned behavior was selected to create and improve the Pap smear screening behavior among women in Fasa city. This model has been employed in numerous studies. For instance, Matlabi et al. [11] in their study conducted on 140 married women aged between 20 and 49 years old to explore the impact of education on the promotion of breast self-examination using the stages of change model. The results revealed a significant increase in the means of knowledge, attitude, perceived behavioral control, behavioral intention, and breast self-examination behavior in the intervention group after the educational intervention. However, no significant changes were observed in the control group. These results confirmed the effectiveness of the educational intervention on the promotion of breast self-examination behavior as a screening method for breast cancer [11]. Similarly, Taghdisi et al. (2016) assessed the effect of an educational intervention on the improvement of the consumption of fruits and vegetables among students based on a behavioral theory. The results showed an increase in the intervention group's knowledge, attitude, perceived behavioral control, and subjective norms compared to the control group after the intervention, which consequently promoted the consumption of fruits and vegetables [12]. In the same vein, Jeihooni et al. [13], based on a behavioral theory, evaluated the effect of an educational intervention on the performance of mammography as a breast cancer screening technique. The results indicated a significant increase in the intervention group's knowledge, attitude, perceived behavioral control, and subjective norms compared to the control group by passing 6 months from the intervention. After the intervention, $78 \%$ of the women in the intervention group were willing to perform mammography and $74 \%$ finally did that. Accordingly, these measures were obtained as $19 \%$ and $7 \%$ in the control group, respectively. Hence, the educational intervention based on the behavioral theory was effective on the improvement of the performance of mammography among the women [13]. The theory of planned behavior pays attention to social factors and motivation for following the significant ones. Hence, various studies have found it as an important factor in the acceptance of desirable behaviors like performing the Pap smear test $[14,15]$. Considering the importance of Pap smear screening for early detection of cancer cervix in women, the need for educational intervention to increase participation in performing this test, and due to the fact that no intervention study has been conducted in this regard in Fasa city so far, the present study aimed to investigate the effect of an educational program on increasing cervical cancer screening behavior based on the Theory of Planned Behavior (TPB) among women in Fasa city, Fars province, Iran.

\section{Methods \\ Design}

This descriptive-analytical, cross-sectional study was conducted in Fasa in 2016.

\section{Sample and setting}

Of six healthcare centers in Fasa, two centers were selected through simple random sampling. Thereafter, 
based on the lists of the households covered by each center, 350 people were selected from each center via simple random sampling (700 people in total) who were then enrolled into the research. During the sampling, two researcher's assistants were present in the healthcare centers, provided the eligible women with the necessary information, invited them to take part in the research, and finally obtained their written informed consent forms. The inclusion criteria of the study were the followings: being married, age above 21 years old, married at least 3 years ago, having no history of cancer and hysterectomy, and not having performing the Pap smear test during the past 3 years. The exclusion criterion of the study was the absence in the 3-month follow-up.

At first, a cross-sectional study was conducted on 700 participants [16]. Subsequently, they were requested to fill out the demographic information and theory of planned behavior questionnaires. The obtained results were analyzed and the educational intervention was designed. Next, the educational intervention was conducted in a workshop form for 50 women as the intervention group and 50 women as the control group (Fig. 1 shows the study flowchart).

\section{Measures}

The study data were collected using an instrument including three sections, which was prepared based on the Moradi et al. [16] and Roncancio et al. [17] studies that its validity and reliability were confirmed. The first part of the questionnaire contained demographic information such as age, number of children, age at the time of the first pregnancy, history of performance of the Pap

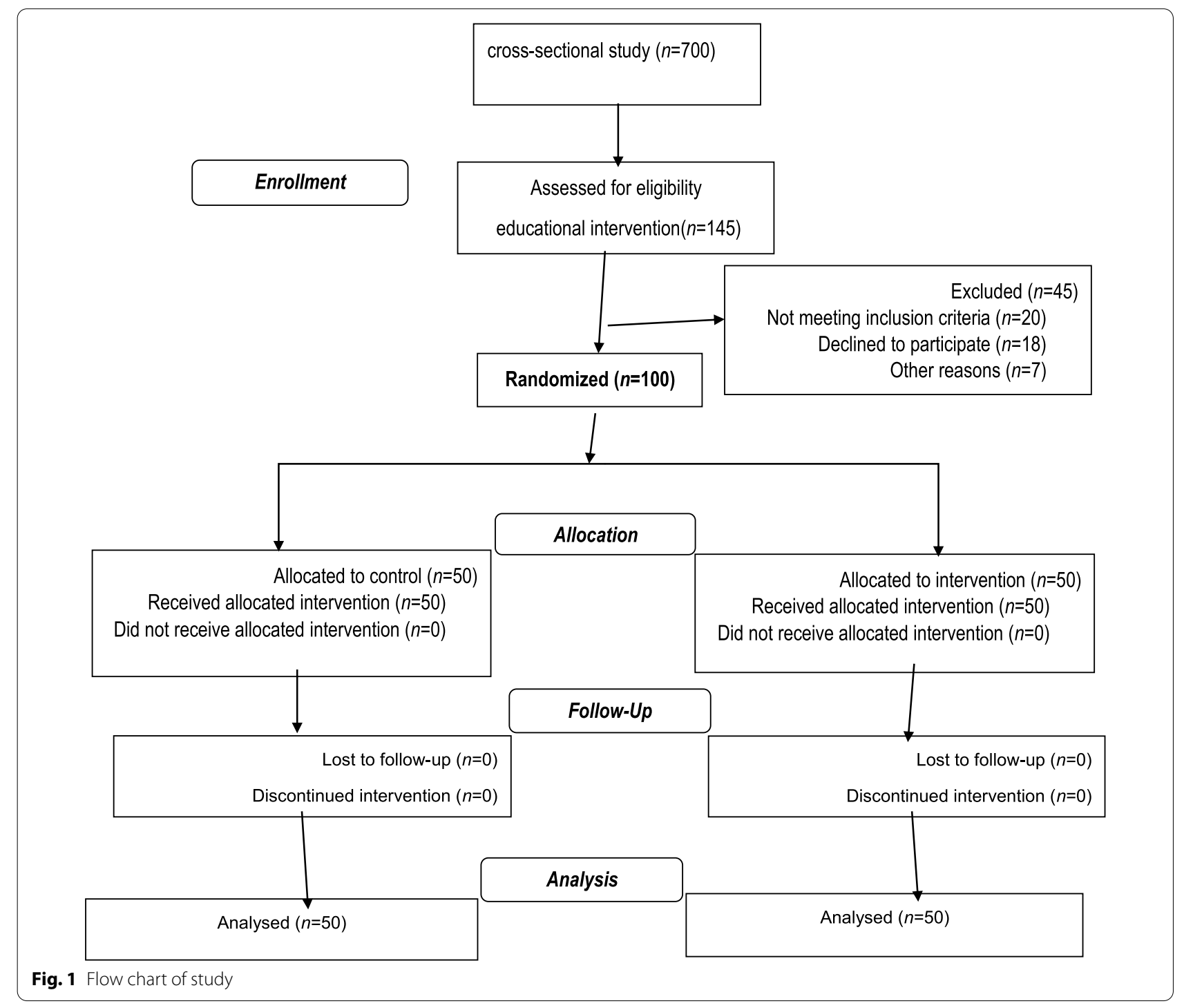


smear test, occupation, educational level, menopause status, and family history of cervical cancer. The second and third parts of the questionnaire consisted of some questions on knowledge and the constructs of the theory of planned behavior. In this questionnaire, knowledge was assessed by 15 yes/no questions (yes $=1$, no $=0$ ). in addition, attitude was evaluated by six items (e.g. Annually performing the Pap smear test reduces the probability of cervical cancer) responded via a five-option Likert scale ranged from completely disagree [1] to completely agree [5]. Moreover, subjective norms of the persuasive person for performance of the Pap smear test were determined by five items (e.g. My husband persuades me to perform the Pap smear test on a regular basis) responded through a five-option Likert scale ranged from very low [1] to very high [5]. Besides, perceived behavioral control was measured by two items (e.g. Performance of the Pap smear test is difficult for me) responded using a five-point Likert scale ranged from very low [1] to very high [5]. Intention to perform the Pap smear test was also evaluated using two items (e.g. I intend to perform the Pap smear test this year) responded via a five-option Likert scale ranged from very low [1] to very high [5]. Finally, screening behaviors and performance of the Pap smear test were both assessed via two items whose scores ranged from 2 to 18 . The content validity of the questionnaire was assessed by 18 health education specialists, one MSc of midwifery, and one gynecologist. Considering Content Validity Ratio (CVR) and Content Validity Index (CVI), the necessary modifications were applied and the indices were then confirmed. Moreover, a pilot study was conducted on 30 eligible women. Notably, the reliability coefficients of attitude, subjective norms, behavioral intention, and perceived behavioral control constructs were found to be $0.74,0.75,0.65$, and 0.76 respectively.

Subsequently, the study data were entered into the SPSS 22 software and then analyzed using Pearson's correlation coefficient and logistic regression analysis. $P<0.05$ was considered as statistically significant.

\section{Intervention}

The educational intervention was conducted through lecture, group discussion, question and answer, educational pamphlets and posters, movie, and PowerPoint in form of three 45-min sessions. Accordingly, these educational sessions were held once a week. In the third session, physicians, healthcare staff, and the participants' husbands were present as subjective norms. The educational content included cervical cancer, importance of performing screening behaviors, probable obstacles against the performance of the Pap smear test, and strategies for overcoming individual and environmental barriers. The intervention was performed through face-to-face training, group discussion (about beliefs, positive and negative outcomes of the behavior, facilitators, motivation to follow the significant ones, and subjective norms), educational pamphlets, and PowerPoint. In addition, an educational movie on how the Pap smear test is done, was shown for the participants. The discussions were directed towards the identification of positive beliefs and attitudes, in order to promote positive motivation for performing diagnostic measures, particularly the Pap smear test, and to provide the ground for development of a positive attitude or modification of the negative attitude on the uncontrollability of the disease. Moreover, some wrong beliefs about the Pap smear test that are common were put under debate, in order to reduce the intensity of wrong beliefs by modifying the participants' beliefs and attitudes. At the end of the educational sessions, the participants were provided with an educational booklet. Besides, a WhatsApp group was created for information's sharing. An informed SMS was also sent to the participants once a week. However, in the control group, the participants were provided only with the educational booklet.

\section{Statistical analysis}

All the participants were followed up until 3 months after the educational intervention and the theory of planned behavior questionnaire was completed for them once again. Furthermore, they were required to send the results of their Pap smear tests to the researcher in case that they performed the test. Afterward, the data were entered into the SPSS statistical software and then analyzed via logistic regressions analysis, paired $t$ test, independent $t$ test, chi-square test, and McNemar test.

\section{Ethics}

This study was approved by the Research Council (code: 95,094) and Ethics Committee (IR.FUMS.REC.1396.187) of Fasa University of Medical Sciences. It was also registered in the Iranian Registry of Clinical Trials (IRCT20160830029608N3).

\section{Results}

In the present research, 100 women $(50$ subjects for the experimental group and 50 subjects for the control group) were investigated under cover of health centers of Fasa city. None of the cases was excluded from the intervention and control groups. The average age of experimental group was $10.17 \pm 35.62$ years old and average age of the control group was $9.55 \pm 34.12$ years old. Notably, based on the result of independent $t$ test, no significant differences were found between the experimental and control groups $(P=0.154)$. Additionally, demographic 
characteristics of the subjects were not significantly different (Table 1).

The results reveal that, before educational intervention, there were no significant differences between the experimental and control groups in knowledge, attitude, subjective norms, and perceived behavioral control. However, by passing 3 months from the intervention, the experimental group showed significant enhancement in each one of the above-mentioned factors in which the experimental group indicated more significant reduction compared to the control group (Table 2).

The results reveal no significant difference between these two groups concerning the behavioral intention $(p=0.41)$ and performance of the Pap smear test $(p=0.583)$ (Tables 2,3$)$. The number of the participants undergone the Pap smear test increased from 10 to 26 in the intervention group by passing 3 months from the intervention. Accordingly, the results of McNemar test indicated that this difference was statistically significant $(p<0.001$, Table 3$)$.

\section{Discussion}

Numerous studies have demonstrated that the most important reasons for not performing the Pap smear test are insufficient education, lack of knowledge on cervical cancer and the Pap smear test, negative attitude towards examination, cultural problems, incorrect perception of the disease, psychosocial factors, and demographic features. Considering the women's low knowledge level and inappropriate performance in this regard, proper training and interventions seem to play pivotal roles in enhancing their knowledge level and promoting their participation in the Pap smear test to prevent cervical cancer $[18,19]$.

Table 1 Comparison of qualitative variables in two groups of intervention and control women

\begin{tabular}{llll}
\hline Variable & Group & & \\
\cline { 2 - 4 } & $\begin{array}{l}\text { Case }(\mathbf{n}=\mathbf{5 0}) \\
\text { Mean } \pm \text { SD }\end{array}$ & $\begin{array}{l}\text { Control }(\mathbf{n}=\mathbf{5 0}) \\
\text { Mean } \pm \text { SD }\end{array}$ & $\boldsymbol{p}$ value \\
\hline Age & $35.62 \pm 10.17$ & $34.12 \pm 9.55$ & 0.154 \\
Education & & & 0.253 \\
Elementary & $6(12)$ & $5(10)$ & \\
Intermediate & $25(50)$ & $23(46)$ & \\
High school & $18(36)$ & $20(40)$ & 0.345 \\
Collegiate & $1(2)$ & $2(4)$ & \\
Job & & $45(90)$ & \\
Housewife & $44(88)$ & $5(10)$ & \\
Employed & $6(12)$ & & \\
\hline
\end{tabular}

Numbers in parentheses show percent
Table 2 Comparison of mean scores of planned behavior theory in the two groups before and 3 months after the educational intervention

\begin{tabular}{|c|c|c|c|}
\hline TPB constructs & $\begin{array}{l}\text { Before } \\
\text { the intervention }\end{array}$ & $\begin{array}{l}\text { Three months } \\
\text { after the intervention }\end{array}$ & $p$ value \\
\hline \multicolumn{4}{|l|}{ Attitude } \\
\hline Control & $3.34 \pm 20.25$ & $3.28 \pm 20.6$ & 0.19 \\
\hline Case & $3.25 \pm 20.68$ & $2.35 \pm 25.58$ & $P<0 / 001$ \\
\hline$p$ value & 0.18 & $P<0 / 001$ & \\
\hline \multicolumn{4}{|l|}{ Subjective norms } \\
\hline Control & $3.60 \pm 14.14$ & $3.45 \pm 14.21$ & 0.23 \\
\hline Case & $3.64 \pm 14.18$ & $3.28 \pm 18.33$ & $P<0.001$ \\
\hline$p$ value & 0.68 & $P<0.001$ & \\
\hline \multicolumn{4}{|c|}{ Perceived behavioral control } \\
\hline Control & $1.00 \pm 5.74$ & $1.12 \pm 5.80$ & 0.35 \\
\hline Case & $1.00 \pm 5.82$ & $2.11 \pm 8.89$ & $P<0.001$ \\
\hline$P$ value & 0.65 & $P<0.001$ & \\
\hline Control & $2.14 \pm 5.78$ & $2.31 \pm 5.85$ & 0.41 \\
\hline Case & $2.35 \pm 5.34$ & $2.12 \pm 9.45$ & $P<0.001$ \\
\hline Pvalue & 0.76 & $P<0.001$ & \\
\hline \multicolumn{4}{|l|}{ Behavioral intent } \\
\hline Control & $3.34 \pm 20.25$ & $3.28 \pm 20.6$ & 0.19 \\
\hline Case & $3.25 \pm 20.68$ & $2.35 \pm 25.58$ & $P<0 / 001$ \\
\hline$P$ value & 0.18 & $P<0 / 001$ & \\
\hline
\end{tabular}

Bahmani et al. in their study, based on the precaution adoption process model, investigated the effect of an educational intervention on the cervical cancer screening behavior. The results revealed the effectiveness of this model on the improvement of the cervical cancer screening behavior. Although the utilized educational intervention was different from the one used in the present study, the results of both studies indicated that educational interventions could promote health-related behaviors in the community [20]. Hazavehei et al. (2016) in a systematic review have also explored the impact of educational interventions on enhancing Pap smear screening. Among the investigated articles, seven of them were conducted

Table 3 Frequency distribution of Pap smear test before and after the educational intervention

\begin{tabular}{llll}
\hline Variable & Case $(\mathbf{n = 5 0 )}$ & Control $(\mathbf{n = 5 0 )}$ & $\boldsymbol{p}$ value \\
\hline $\begin{array}{l}\text { Before the intervention } \\
\text { Pap smear }\end{array} 10(20)$ & $8(16)$ & $P=0.583$ \\
$\begin{array}{l}\text { Failure to do pap } \\
\text { After the intervention }\end{array}$ & $40(80)$ & $42(84)$ & \\
$\begin{array}{l}\text { Pap smear } \\
\text { Failure to do pap }\end{array}$ & $26(52)$ & $10(20)$ & $P<0 / 001$ \\
\hline
\end{tabular}

Numbers in parentheses show percent 
using health education theories and models, while five of them were performed without the use of these theories and models. The findings demonstrated that the utilization of multifaceted educational methods as well as the application of health education and health promotion theories and models are highly effective on the improvement of individuals' behavioral performances. As mentioned earlier, health education and health promotion interventions play critical roles in the elimination of problems and in the promotion of behaviors like performance of the Pap smear test. When these interventions are accomplished based on models and theories, finding the constructs under the influence of the theories and models can help in designing interventions for the promotion of the behavior. This can, in turn, play a key role in the evaluation and documentation of change strategies [18].

The results of a meta-analysis conducted by $\mathrm{Naz}$ et al. revealed the effectiveness of educational interventions based on health behavior change theories on the improvement of women's behavior regarding the performance of cervical cancer screening worldwide. In this respect, the theory of planned behavior was found to be a beneficial model for determining the women's tendency to perform cervical cancer screening. Overall, theory-based educational interventions could increase the women's knowledge in this field and also enhance their intention to perform the cervical cancer screening test [21]. The findings of a meta-analysis by Steinmetz et al. [22] have also proved the effectiveness of the interventions based on the theory of planned behavior on behavior change. These results were in agreement with those of the current investigation.

Ebu et al. [23] assessed the effect of planned interventions based on the health belief model on breast cancer and cervical cancer screening as well as the performance of the Pap smear test among 870 women. Correspondingly, the results indicated an increase in the women's intention to perform Pap smear test after the intervention. Although the utilized method was different from that employed in the present study, the results confirmed the positive effect of educational interventions on the promotion of cancer prevention methods among women.

Molaei-Zardanjani et al. in their study reported that education based on the theory of planned behavior (either in person or in groups) was effective on the women's attitude, subjective norms, perceived behavioral control, and behavioral intention regarding the performance of mammography. In fact, the educational intervention improved the breast cancer screening behavior, which was in line with the results of the present study [24].

Karakuş Selçuk and Yanikkerem investigated the effect of education on the women's attitude and behavior regarding breast cancer and cervical cancer screening. Accordingly, the results showed that $28.4 \%$ of the women performed mammography, $69.9 \%$ performed breast self-examination, and $33.6 \%$ of them performed the Pap smear test 6 months after the intervention. Hence, the training was found to be effective on the promotion of the women's attitude and behavior regarding the performance of screening. Although the used educational method was not similar to that utilized in the current study, the results indicated the women's need for a professional educational program, in order to improve their attitude and behavior regarding screening programs [25].

The results of Abamecha et al's study showed that the rate of knowledge of the disease signs, symptoms, risk factors, and prevention methods was 162(41.4\%). Moreover, knowledge on the disease and past screening experience were positively associated with the intention to use cervical cancer screening. Furthermore, standardized regression coefficient showed that all dimensions of TPB were positively associated with the intention to use the services with perceived behavioral control, perceived social pressure, and attitude towards screening [26].

In Mirzaei-Alavijeh et al's study, 3 months after the educational intervention, significant improvements were found in average response for Attitude, subjective norms, perceived behavior control, and behavioral intention toward undergoing Pap smear among the intervention group. Additionally, after the intervention, the rate of intention to perform Pap smear test has increased among the intervention group. This study indicated that the educational program based on theory of planned behavior could encourage women to do Pap smear test regularly [27].

Some of the limitations of this study were self-reporting answers of the included subjects and lack of accurate answers to some questions due to shame feeling. Of course, the subjects were ensured that their information would remain confidential. Considering the fact that sampling in this study was performed from those people referred to health centers and not based on population, the study does not have a good external validity. In addition, the generalization of the results to other places should be done with caution. In this regard, performing population-based studies is recommended. The strong points of the research included the creation of the WhatsApp group, continual repetition of the trainings, and reception of the Pap smear test results besides the women's report of performance of the test.

\section{Conclusion}

The results of this research indicate that educational intervention based on theory of planned behavior led to the enhancement of knowledge, positive attitude, 
self-subjective norms, perceived behavioral control, and behavioral intention in the studied subjects, which consequently caused the promotion of performance of the Pap smear test of the studied women. Therefore, for performing the Pap smear test among women, theory of planned behavior is recommended. It is noteworthy that engaging families and health officials such as doctors and health workers in educational programs, providing places for performing Pap smear test for women would have a great effect on performance of the Pap smear test.

\section{Abbreviations}

TPB: Theory of planned behavior; CPU: Central Processing unit.

\section{Authors' contributions}

MHS, AKHJ, ZM and AD assisted in conceptualization and design of the study, oversaw data collection, conducted data analysis and drafted the manuscript. MHS and ZM conceptualized and designed the study, assisted in data analysis and reviewed the manuscript. MHS, AKHJ, ZM and AD assisted in study conceptualization and reviewed the manuscript. All authors read and approved the final manuscript.

\section{Funding}

Research reported in this article was jointly supported by Fasa university of medical sciences.

\section{Availability of data and materials}

The datasets used and/or analyzed during the current study are available from the corresponding author upon reasonable request.

\section{Ethics approval and consent to participate}

Ethical approval was obtained from the Human Research Ethics Committee at the Fasa University of Medical Sciences (IR.FUMS.REC.1396.187). All study participants provided written informed consent. Permission was also obtained to digitally record all interview. Confidentiality and anonymity were ensured.

\section{Consent for publication}

Not applicable.

\section{Competing interests}

The authors declare that they have no competing interests.

\author{
Author details \\ ${ }^{1}$ Shiraz University of Medical Sciences, Shiraz, Iran. ${ }^{2}$ Department of Public \\ Health, School of Health, Shiraz University of Medical Sciences, Shiraz, Iran. \\ ${ }^{3}$ Department of Nursing, School of Nursing, Fasa University of Medical Sci- \\ ences, Fasa, Iran. ${ }^{4}$ No Communicable Diseases Research Center, Fasa Univer- \\ sity of Medical Sciences, Fasa, Iran.
}

Received: 15 August 2020 Accepted: 21 January 2021

Published online: 28 January 2021

\section{References}

1. Momenimovahed Z, Salehiniya H. Cervical cancer in Iran: integrative insights of epidemiological analysis. BioMedicine. 2018. https://doi. org/10.1051/bmdcn/2018080318.

2. Sharifi M, Mohammadi Z, Makvandi Z, Rostami P, Moradi A. Assessment of cervical cancer screening and its barriers in 18-50 year old women referring to Asad Abad comprehensive health centers. Pajouhan Sci J. 2018;16(2):1-9. https://doi.org/10.21859/psj.16.2.35.

3. Burkman RT. Berek and Novak's gynecology. JAMA. 2012;308(5):516-7. https://doi.org/10.1001/jama.308.5.516.

4. Kolutek R, Avcl IA. The effect of training and monitoring at home on the knowledge level and practices of married women regarding breast and cervical cancer. J Breast Health. 2015;11(4):155. https://doi.org/10.5152/ tjbh.2015.2647.

5. Evangelista Rodrigues D, Alves Moreira KF, Souza de Oliveira T. Barriers to prevention of cervical cancer in the city of Porto Velho, Rondônia, Brazil. Investigación y Educación en Enfermería. 2016;34(1):59-67. https://doi. org/10.17533/udea.iee.v34n1a07.

6. Berek JS, Crum C, Friedlander M. Cancer of the ovary, fallopian tube, and peritoneum. Int J Gynecol Obstet. 2012;119:S118-29. https://doi. org/10.1016/S0020-7292(12)60025-3.

7. Rossmann C. Theory of reasoned action-theory of planned behavior. Baden-Baden: Nomos Verlagsgesellschaft mbH \& Co. KG; 2010. https:// doi.org/10.5771/9783845260341.

8. An L, Liu C, Zhang N, Chen Z, Ren D, Yuan F, et al. GRIK3 rs490647 is a common genetic variant between personality and subjective well-being in Chinese Han population. A/A. 2019;296:33.3. Corpus ID: 199418602

9. Hambardzumyan M, Hayrapetyan A. Differential diagnosis of malignant melanoma and benign cutaneous lesions by ultrasound analysis. SciMed J. 2020;2(2):100-7. https://doi.org/10.28991/SciMedJ-2020-0202-7.

10. Zare $H$. Effects of salvia officinalis extract on the breast cancer cell line. SciMed J. 2019;1(1):25-9. https://doi.org/10.28991/SciMedJ-2019-0101-4.

11. Matlabi M, Khajavi A, Askari F, Saberi M. Breast self-examination and the role of education based on stages of change model in changing women's decision. Iran J Obstet Gynecol Infertil. 2018;21(1):42-51.

12. Taghdis MH, Babazadeh T, Moradi F, Shariat F. Effect of educational intervention on the fruit and vegetables consumption among the students: applying theory of planned behavior. J Res Health Sci. 2016;16(4):195.

13. Jeihooni AK, Darvishi N, Harsini PA. The effect of educational intervention based on the theory of planned behavior on mammography screening in Iranian women. J Cancer Educ. 2019. https://doi.org/10.1007/s1318 7-018-1460-3.

14. Arshad SM, Khani-jeihooni A, Moradi Z, Kouhpayeh SA, Kashfi SM, Dehghan A. Effect of theory of planned behavior-based educational intervention on breastfeeding behavior in pregnant women in Fasa City, Iran. J Educ Community Health. 2017;4(2):55-63. https://doi.org/10.21859 /jech.4.2.55.

15. Eslamimehr F, Rakhshani F, Ramezan Khani A, Khodakarim S. The examination of the effectiveness of an educational intervention based on the planned behavior theory on improving pubertal health behavior in female high school students. Int J Pediatrics. 2017;5(9):5643-54. https:// doi.org/10.22038/ijp.2017.24027.2028.

16. Moradi Z, Moradi P, Khani Jeihooni A, Dehghan A. Factors associated with pap smear implementation among women referring to healthcare centers in Fasa, Iran: an application of theory of planned behavior. J Educ Community Health. 2017;4(1):51-8. https://doi.org/10.21859/jech.4.1.51.

17. Roncancio AM, Ward KK, Sanchez IA, Cano MA, Byrd TL, Vernon SW, et al. Using the theory of planned behavior to understand cervical cancer screening among Latinas. Health Educ Behav. 2015;42(5):621-6. https:// doi.org/10.1177/1090198115571364.

18. Hazavehei M, Dogonchi M, Ezati Rastegar K, Gheysvandi E, Salimi N. The impact of educational interventions to increase screening Pap smear: a systematic review. J North Khorasan Univ Med Sci. 2017;9(2):203-18. https://doi.org/10.18869/acadpub.jnkums.9.2.203.

19. Shanbhag $S$, Joseph RC. A study of maternal breast feeding issues during early postnatal days. SciMed J. 2020;2(4):219-24. https://doi.org/10.28991 /SciMedJ-2020-0204-4.

20. Bahmani A, Bahmani N, Enjezab B, Baghianimoghadam $\mathrm{H}$, Mahmoodabad SSM. Survey the effect of educational program based on precaution adoption process model on screening cervical cancer behaviors among rural women, mixed method development. J Pharm Res Int. 2019. https://doi.org/10.9734/JPRI/2019/v27i130158.

21. Naz MSG, Kariman N, Ebadi A, Ozgoli G, Ghasemi V, Fakari FR. Educational interventions for cervical cancer screening behavior of women: a systematic review. Asian Pac J Cancer Prev APJCP. 2018;19(4):875. https:// doi.org/10.22034/APJCP.2018.19.4.875.

22. Steinmetz H, Knappstein M, Ajzen I, Schmidt P, Kabst R. How effective are behavior change interventions based on the theory of planned behavior? Zeitschrift für Psychologie. 2016. https://doi.org/10.1027/2151-2604/ a000255.

23. Ebu NI, Amissah-Essel S, Asiedu C, Akaba S, Pereko KA. Impact of health education intervention on knowledge and perception of cervical cancer 
and screening for women in Ghana. BMC Public Health. 2019;19(1):1505. https://doi.org/10.1186/s12889-019-7867-x.

24. Molaei-Zardanjani M, Savabi-Esfahani M, Taleghani F. Comparing individual and peer education on the constructs of theory of planned behavior in mammography. J Educ Health Promot. 2019. https://doi.org/10.4103/ jehp.jehp_138_18.

25. Karakuş Selçuk A, Yanikkerem E. The effect of web-based education on Pap smear behaviours of teachers. Eur J Cancer Care. 2020;29(3):e13202. https://doi.org/10.1111/ecc.13202.

26. Abamecha F, Tena A, Kiros G. Psychographic predictors of intention to use cervical cancer screening services among women attending maternal and child health services in Southern Ethiopia: the theory of planned behavior (TPB) perspective. BMC Public Health. 2019;19(1):434. https:// doi.org/10.1186/s12889-019-6745-X.

27. Mirzaei-Alavijeh M, Karami-Matin B, Jalilian F, Rakhshani F, Mahboubi M, Emdadi S. Pap smear test promotion among women: an Educa-tional intervention based on theory of planned be-havior. J Biol Today's World. 2014;3(4):100-3.

\section{Publisher's Note}

Springer Nature remains neutral with regard to jurisdictional claims in published maps and institutional affiliations.
Ready to submit your research? Choose BMC and benefit from:

- fast, convenient online submission

- thorough peer review by experienced researchers in your field

- rapid publication on acceptance

- support for research data, including large and complex data types

- gold Open Access which fosters wider collaboration and increased citations

- maximum visibility for your research: over 100M website views per year

At BMC, research is always in progress.

Learn more biomedcentral.com/submissions 